\title{
Disseminated verrucous porokeratosis successfully treated with 5-FU followed by oral isotretinoin- a
}

\section{case report}

\begin{abstract}
Introduction: Multiple clinical variants of porokeratosis are known. The verrucous variant is usually confined to the buttocks (porokeratosis ptychotropica) and is one of the less commonly reported entities.

Case description: We report a case of disseminated verrucous porokeratosis involving almost any area of the body, mostly the upper trunk, successfully treated with oral retinoids following topical 5-FU.

Discussion: Histological examination is crucial for the diagnosis. The observation of multiple cornoid lamellae and the absence of other characteristic findings establish the diagnosis. Several therapeutic modalities have been described; therefore the approach to treatment must be individualized. Our case adds to the growing list of porokeratosis' variants and suggests that oral retinoids following topical 5-FU is a good therapeutic alternative in the treatment of the disease.
\end{abstract}

Volume 2 Issue 5 - 2018

\author{
Vasiliki Markantoni,' Eftychia Platsidaki,' \\ Anargyros Kouris,' Kiriaki Aroni, ${ }^{2}$ Georgios \\ Kontochristopoulos' \\ 'Department of Dermatology and Venereology, Andreas Sygros \\ Skin Hospital, Greece \\ ${ }^{2}$ Private Dermatology Clinic, Greece
}

Correspondence: Eftychia Platsidaki, Department of Dermatology and Venereology, Andreas Sygros Skin Hospital, 5 lonos dragoumi str,Athens, I6121, Greece, Email platsidakieft@yahoo.com

Received: August 13,2018 | Published: September 12, 2018

Keywords: porokeratosis, disseminated, verrucous

\section{Introduction}

Porokeratosis represents a group of disorders of abnormal epidermal keratinization that shares the distinctive histopathologic feature of the cornoid lamella. ${ }^{1}$ The typical lesion of porokerastosis is characterized by an atrophic center surrounded by an elevated keratotic rim. The most common clinical forms are: classic porokeratosis of Mibelli (PM), disseminated superficial actinic porokeratosis (DSAP), linear porokeratosis, porokeratosis palmaris et plantaris disseminata (PPPD) and punctate porokeratosis. ${ }^{1}$ A less commonly reported clinical variant is verrucous porokeratosis resembling psoriasis usually confined to the buttocks (porokeratosis ptychotropica). ${ }^{2} \mathrm{We}$ report a case of verrucous porokeratosis involving almost every area of the body, mostly the upper trunk.

\section{Clinical case}

A 36-year-oldwhite woman presented with numerous, asymptomatic, hyperkeratotic, vitiliginous papules and plaques widespread on the trunk, mostly on the back and shoulders, with progressive growth (Figure 1). She reported that lesions had been present for more than 3years. She has been previously given an unclear diagnosis of plaque psoriasis, keratosis pilaris and lichen planus. In the past she was treated with topical corticosteroids without any significant improvement. Moreover, she had no past medical history or family history of a similar rash. Dermoscopy showed a "white track" structure (Figure 2). Histopathological examination revealed multiple cornoid lamellae with diminution of the granular layer, hyperkeratosis and acanthosis of the epidermis even between cornoid lamellae (Figure 3). Blood and serology tests were normal. Based on clinical and histopathological findings the diagnosis of verrucous porokeratosis with an atypical widespread distribution was made. Patient was initially treated with topical 5-FU, which induced partial remission after two weeks. Despite the semi-effectiveness of this treatment, we decided to add oral retinoid a month later. At the same time, we discontinued topical 5-FU due to mild local irritation and the potential risk for systemic absorption because of its large area of application. After 3months of treatment (oral isotretinoin $20 \mathrm{mg}$ daily) patient had an excellent response (Figure 4). During followup visits at 1 and 3 months after discontinuation of treatment, no recurrence was observed.

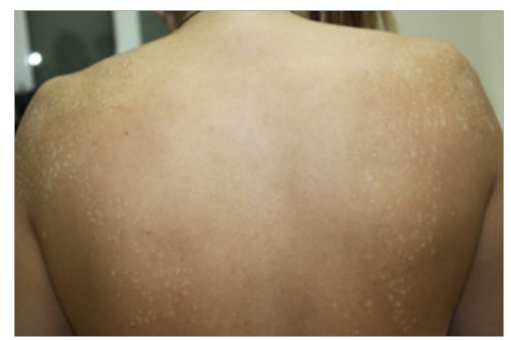

Figure I Disseminated verrucous porokeratosis: Numerous hyperkeratotic, vitiliginous papules and plaques widespread on the trunk.

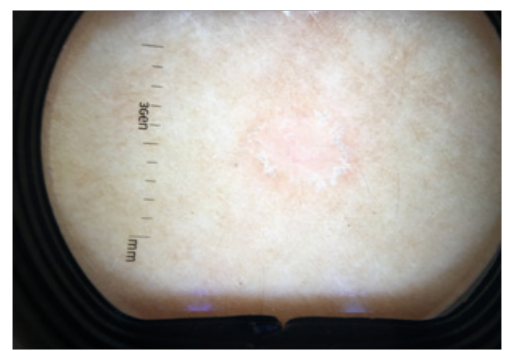

Figure 2 Digital dermoscopy: a well demarcated "white -yellow track" structure.

\section{Discussion}

The verrucous variant of porokeratosis is very rare and usually is localized to the perinatal cleft and extending to the buttocks. ${ }^{2}$ In 1995 , Lucker et al., ${ }^{3}$ described the first case of porokeratosis ptychotropica using the Greek words ptyche (fold) and trope (a turning) to describe 
the flexural distribution of this condition. ${ }^{3}$ Since then few similar cases have been recorded. Two cases have described the coexistence of different variants of porokeratosis in the same individual ${ }^{4,5}$ and only one case of porokeratosis involving almost all parts of the body with simultaneous occurrence of various subtypes of the disease. Our patient represents an unusual presentation of porokeratosis, a disseminated verrucous porokeratosis subtype. The differential diagnoses include plaque psoriasis, lichen planus and common warts. Risk factors for porokeratosis include family history, light-colored skin, ultraviolet or ionizing radiation exposure, internal malignancies and immunosuppression. ${ }^{8}$

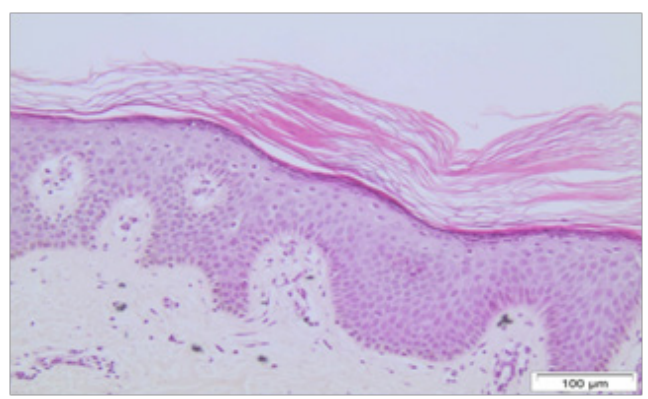

Figure 3 Histopathology evidenced the presence of multiple cornoid lamellae.

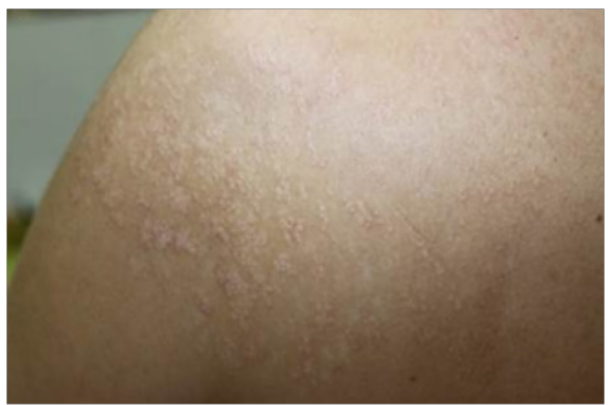

Figure 4 Evident clinical improvement after treatment, initially with topical $5-\mathrm{FU}$ and subsequently with oral isotretinoin.

Histological examination is crucial for the diagnosis. The observation of multiple cornoid lamellae and the absence of other characteristic findings establish the diagnosis. ${ }^{9}$ Multiple layers of concentric cornoid lamellae, as in our case, probably contribute to the verrucoid appearance of this variant of porokeratosis. Dermoscopy reveals an annular white-yellow structure demarcating a central scar like area surrounded by minimal peripheral vascularization. ${ }^{10}$

Several therapeutic modalities have been described, ranging from topical, such as keratolytic agents, imiquimod, tretinoin, 5-FU, to oral retinoid, cryotherapy, photodynamic therapy, and carbon dioxide laser and surgical excision. ${ }^{11}$ However, lesions are often either unresponsive or refractory to therapy. The approach to treatment should be individualized, based on the size of the lesion and the anatomical location, the functional and aesthetic considerations, the risk of malignancy and the patient's preference. Although most clinical variants of porokeratosis have the potential for transformation into squamous or basal cell carcinoma, the verrucous subtype has not been reported to transform.
The successful treatment of our patient with topical 5-FU followed by oral retinoid is in keeping with previous published findings. ${ }^{12}$ 5-FU interferes with DNA synthesis and to a lesser extent RNA synthesis. This mechanism of action seems to influence epidermal keratinization which is the main disturbance of porokeratosis. The risk of absorption is insignificant; however when used in large surfaces the risk rate increases. The use of systemic retinoid maintains the remission probably by promoting the normalization of the pattern of keratinization. This case adds to the growing list of the variants of porokeratosis and suggests that oral retinoid following topical 5-FU is a good therapeutic option.

\section{Acknowledgements}

None.

\section{Conflict of interest}

Author declares that there is no conflict of interest.

\section{References}

1. Disorders of epidermal differentiation and keratinization: porokeratosis. Fitzpatrick's dermatology in general medicine. $8^{\text {th }}$ ed. New York: McGraw-Hill Medical. 2012;563-568.

2. D'souza P, Dhali TK, Arora S, et al. Porokeratosis ptychotropica: a rare variant of porokeratosis. Dermatol Online J. 2014;20(6).

3. Lucker GP, Happle R, Steijlen PM. An unusual case of porokeratosis involving the natal cleft: porokeratosisptychotropica? $\mathrm{Br} J$ Dermatol. 1995;132(1):150-151.

4. Guo H, Gao XH, Chen HD, et al. Coexistence of multiple variants of porokeratosis. Indian J Dermatol Venereol Leprol. 2015;81(4):402-403.

5. Ma Y, Li C, Wu J, et al. Coexistence of porokeratosisptychotropica with porokeratosis of Mibelli in a Chinese man. Postepy Dermatol Alergol. 2015;32(4):307-309.

6. Bhaskar S, Jaiswal AK, Raj N, et al. Porokeratosis-Head to toe: An unusual presentation. Indian Dermatol Online J. 2015;6(2):101-104.

7. Veasey JV, Dalapicola MC, Lellis RF, et al. Porokeratosis ptychotropica: a rare manifestation with typical histological exam. An Bras Dermatol. 2016;91(4):496-498.

8. Sertznig P, von Felbert V, Megahed M. Porokeratosis: present concepts. $J$ Eur Acad Dermatol Venereol. 2012;26(4):404-412.

9. Contreras-Ruiz J, Toussaint-Caire S, Torres-Camacho P, et al. Porokeratosis ptychotropica: a diagnostic and therapeutic challenge. $J$ Eur Acad Dermatol Venereol. 2018;32(3):e114-e115.

10. Luo Y, Liu J. Image Gallery: Verrucous porokeratosis with characteristic histopathological and dermoscopic features. $\mathrm{Br} J$ Dermatol. 2017; 176(4):e38

11. Kawakami Y, Mitsui S. A case of porokeratosis ptychotropica: successful treatment with topical 5\% imiquimod cream. Clin Exp Dermatol. 2017;42(7):839-841.

12. Sander CA, Pfeiffer C, Kligman AM, et al. Chemotherapy for disseminated actinic keratoses with 5-fluorouracil and isotretinoin. $J \mathrm{Am}$ Acad Dermatol. 1997;36(2 Pt 1):236-238. 